\title{
EFEITOS DAS CULTURAS DE MILHO (Zea mays), FEIJÃO (Phaseolus vulgaris) E CAUPI (Vigna unguiculata) NA AGREGAÇÃO DE VALOR AO CULTIVO DA BANANEIRA 'TERRA', EM TEOLÂNDIA, LITORAL SUL DA BAHIA' ${ }^{1}$
}

\author{
MARCELO BEZERRA LIMA², ÉLIO JOSÉ ALVES², ANA LÚCIA BORGES ${ }^{3}$, \\ FREDERICO HILÁRIO DE AZEVEDO NASCIMENTO²
}

\begin{abstract}
RESUMO - São apresentados resultados pertinentes às culturas do milho (Z. mays), feijão (P. vulgaris) e caupi (V. unguiculata) consorciados com bananeira 'Terra' (Musa AAB) em Teolândia, Litoral Sul da Bahia, em cultivo simultâneo, no estabelecimento da bananeira e sucessivo logo após a colheita do primeiro. Os espaçamentos utilizados foram o 4,0 x 2,0 × 3,0 m, 4,0 x 2,0 x 2,6m e 4,0 x 2,0 x 2,8m em fileira dupla, o que permitiu melhor proveito da área pelas culturas intercalares. O milho, ou o feijão, ou o caupi ocupou apenas as ruas entre as fileiras duplas de bananeiras, ficando livres as ruas formadas pelas fileiras duplas, devido ao seu sombreamento pela bananeira ser mais rápido. O objetivo deste trabalho foi avaliar o desempenho das culturas do milho, feijão e caupi na agregação de valor à bananeira 'Terra', quando consorciadas com esta cultura. Nos melhores tratamentos ( $\mathrm{T}_{9}$, $\mathrm{T}_{6}$, $\mathrm{T}_{8}$ e $\mathrm{T}_{4}$ ), o índice de rentabilidade-IR (receita total $\div$ custos) alcançou valores expressivos, de 3,36 até 6,68, resultando em efeitos altamente positivos em decorrência das tecnologias e insumos utilizados, o que vai permitir a agregação de um elevado valor à bananeira e, conseqüentemente, uma boa remuneração ao produtor. Estes resultados indicam que, para cada real investido, houve um retorno de R \$ 3,36 e R \$ 6,68, respectivamente. O IR 0,91 $\left(\mathrm{T}_{2}\right)$, relativo à cultura do milho, implica que houve prejuízo, o que significa que a receita líquida deste tratamento vai reduzir e não incrementar a receita líquida proporcionada pela cultura da bananeira.
\end{abstract}

Termos para Indexação: Cultivos intercalares, produtividade, custos operacionais, receitas, índice de rentabilidade.

\section{EFFECTS OF CORN (Zea mays), BEANS (Phaseolus vulgaris) AND COWPEA (Vigna unguiculata) IN ADDITION OF VALUES PLANTAINS 'TERRA', IN TEOLÂNDIA, SOUTH COAST OF BAHIA}

\begin{abstract}
Results are presented of a intercropping system of corn (Z. mays), beans ( $P$. vulgaris) and cowpea ( $V$. unguiculata) with plantains (Musa AAB) in Teolandia, South Coast of Bahia region in two successive plantations of these crops, being one simultaneous to the establishment of the plantain and the other right after the first harvest. Plants spacing in double rows were used $(4.0 \times 2.0 \times 3.0 \mathrm{~m}, 4.0 \times 2.0 \times 2.6 \mathrm{~m}$ and $4.0 \times 2.0 \times 2.8 \mathrm{~m})$ and were the most efficient space arrangements of intercropping for a longer period of time. Corn, beans or the cowpea, occupied only the rows between the double rows of the plantains, whereas the interrows remained free in order to avoid shading effect of the plantain. The objective of the present work was to evaluate the performance of corn, beans and cowpea crops in addition of values in plantains. Rentability index - RI (total income $\div$ costs) for the best treatments, $\left(\mathrm{T}_{9}, \mathrm{~T}_{6}, \mathrm{~T}_{8}\right.$ and $\left.\mathrm{T}_{4}\right)$, reached significant values of $3.36\left(\mathrm{~T}_{4}\right)$ up to $6.68\left(\mathrm{~T}_{9}\right)$ resulting in positive effects due to technology and fertilizers applied, which allow greater addition of values to the banana crop and, consequently, increase the producers income. A RI of 3.36 and 6.68 means that for each Real (R\$) invested there was a return of $R \$ 3,36$ and $R \$ 6,68$, respectively. RIs lower than 1.0 indicate that the effect of intercrops on the addition of values of bananas crops was negative, resulting in a decrease of net income, which occurred in treatment $\mathrm{T}_{2}$ that presented RI 0.91.
\end{abstract}

Index Terms: Intercropping, yield, operational costs, budgets, lucrative index.

\section{INTRODUÇÃO}

Em regiões produtoras de banana e "plátano" (grupos AAB e ABB), subgrupos Terra/Prata e Figo, seu cultivo pode ser explorado em consórcio com culturas alimentícias transitórias, como milho, feijão, caupi (feijão-de-corda), arroz, mandioca, inhame e batata-doce, com bons resultados.

A necessidade de cultivar duas ou mais culturas na mesma área leva o pequeno produtor a buscar melhores combinações de cultivo, a fim de diversificar a sua produção e obter outras fontes de alimento e renda.

O consórcio de fruteiras com culturas alimentícias anuais (milho, feijão, caupi) tem aumentado bastante em várias regiões do mundo, devido principalmente à grande procura por alimentos, em face do crescimento populacional, da elevação dos preços destes produtos e da necessidade de produzir mais alimentos a custos mais baixos (Belalcázar C. \& Cayón S., 1998).

O consórcio da bananeira e do "plátano" com culturas alimentícias tem sido comum em fazendas familiares e empresariais da África Ocidental, África Oriental, Ásia e Américas Central e do Sul (Robinson, 1995; Alves, 2003).

Na América do Sul, a Colômbia tem se destacado, uma vez que cerca de $98 \%$ dos seus 400.000 ha cultivados com "plátanos" (bananas $\mathrm{AAB}$ e $\mathrm{ABB}$ ) são estabelecidos em 28 sistemas de consórcio, em pequenas propriedades (1 a 15 ha), nas quais mandioca, feijão, milho, caupi, inhame, café e cacau são as mais importantes (Santacruz S. \& Cardona T., 1988; Belalcazár C., 1991; Belalcázar C. \& Cayón S., 1998).

O uso do consórcio permite que sejam obtidas outras fontes de alimento tanto para consumo pelo produtor como para venda, possibilitando, ainda, uma exploração mais intensiva da propriedade, a complementação da dieta alimentar da família, além de agregar valor à cultura principal - a bananeira. Conseqüentemente, o bananicultor pode obter bons resultados com esse sistema de cultivo (Alves \& Coelho, 1984).

O objetivo deste trabalho foi avaliar, do ponto de vista agroeconômico, o desempenho das culturas de milho, feijão e caupi na agregação de valor à bananeira 'Terra', quando consorciadas com esta cultura.

\section{MATERIAL E MÉTODOS}

Um ensaio de sistema de produção de bananeira 'Terra' consorciada com milho (Z. mays), feijão (P. vulgaris) e caupi ( $V$. unguiculata) (feijão-de-corda, macassar) foi instalado na fazenda Alto da Prata, em maio/2002, em Teolândia, Litoral Sul da Bahia, constando dos seguintes tratamentos:

$\mathrm{T}_{1}$ - Bananeira no sistema do produtor, sem consórcio.

$\mathrm{T}_{2}$ - Bananeira no espaçamento 4,0 × 2,0 × 3,0 m, com calagem,

\footnotetext{
${ }^{1}$ (Trabalho 092/2004). Recebido: 15/07/2004. Aceito para publicação: 21/01/2005.

${ }^{2}$ Embrapa Mandioca e Fruticultura. Caixa Postal 007, CEP 44380-000, Cruz das Almas-BA. Fone: (75)621-8041. e-mail: mlima@ cnpmf.embrapa.br.

${ }^{3}$ Embrapa Mandioca e Fruticultura. Caixa Postal 007, CEP 44380-000, Cruz das Almas-BA. Fone: (75)621-8041. e-mail: analucia@ cnpmf.embrapa.br.
} 
mudas tipo chifrinho, três plantas por touceira e milho no espaçamento $1,00 \times 0,20 \mathrm{~m}, \mathrm{com} \mathrm{NPK}$.

$\mathrm{T}_{3}$ - Bananeira no espaçamento 4,0 x 2,0 x 3,0 m, com calagem, mudas tipo chifre, três plantas por touceira, controle fitossanitário e caupi no espaçamento $0,80 \times 0,40 \mathrm{~m}$, com NPK.

$\mathrm{T}_{4}$ - Bananeira no espaçamento 4,0 × 2,0 x 3,0 m, mudas tipo chifrão, três plantas por touceira, controle fitossanitário, calagem, $\mathrm{K}_{2} \mathrm{O}$, cobertura morta nas ruas das fileiras duplas e feijão no espaçamento $0,50 \times 0,10 \mathrm{~m}$, com NPK.

$\mathrm{T}_{5}$ - Bananeira no espaçamento 4,0 x 2,0 x 3,0 m, mudas tipo chifre, três plantas por touceira, controle fitossanitário, adubação orgânica e milho no espaçamento 1,00 x 0,20 m, com NPK.

$\mathrm{T}_{6}$ - Bananeira no espaçamento 4,0 x 2,0 x 3,0 m, mudas tipo chifrão, três plantas por touceira, controle fitossanitário, calagem, adubação orgânica e caupi no espaçamento 0,80 x $\quad 0,40 \mathrm{~m}$, com NPK.

$\mathrm{T}_{7}$ - Bananeira no espaçamento 4,0 × 2,0 x 2,6 m, mudas tipo chifre, duas plantas por touceira, controle fitossanitário, calagem, adubação orgânica, NPK e feijão-de-porco no espaçamento 0,40 x 0,40 $\mathrm{m}$.

$\mathrm{T}_{8}$ - Bananeira no espaçamento 4,0 × 2,00 x 2,8 m, mudas tipo chifrão, três plantas por touceira, controle fitossanitário, calagem, adubação orgânica, NPK e feijão no espaçamento 0,50 x 0,10 m, com NPK.

$\mathrm{T}_{9}$ - Bananeira no espaçamento 4,0 × 2,0 × 3,0 m, mudas micropropagadas, três plantas por touceira, controle fitossanitário, calagem, adubação orgânica, NPK e milho no espaçamento 1,00 x 0,20 m, com NPK

Colhidas as culturas intercalares, estas foram novamente estabelecidas em agosto/2002.

A área total de cada tratamento variou de $572 \mathrm{~m}^{2}$ a $630 \mathrm{~m}^{2}$, para que se possa proceder, posteriormente, a análise econômica dos resultados, inclusive com os resultados relativos à bananeira.

Os coeficientes técnicos previstos para cada produto, para efeito de análise, foram: insumos, plantio, práticas culturais, tratos fitossanitários e colheita.

Os espaçamentos, exceto do tratamento $\mathrm{T}_{1}$, foram em fileiras duplas, recomendados por conservarem praticamente o mesmo número de plantas dos espaçamentos convencionais correspondentes e, principalmente, por permitirem melhor proveito da área pela cultura intercalar e por mais tempo.

Os arranjos espaciais das culturas componentes dos consórcios - bananeira, milho, feijão, caupi - foram esquematizados conforme Figura 1, em relação ao primeiro cultivo, em que as culturas intercalares foram estabelecidas simultaneamente com a bananeira. No segundo cultivo sucessivo, eliminaram-se uma fileira de caupi e duas de feijão, mantendose as duas fileiras de milho.

Os procedimentos utilizados na análise econômica basearamse em Moura (1984) e Devos \& Wilson (1979).

Cada cultura intercalar ocupou apenas as ruas entre as fileiras duplas de bananeiras, ficando livres as ruas formadas pelas fileiras duplas, devido ao seu sombreamento pela bananeira ser mais rápido.

A calagem e as adubações com NPK foram realizadas segundo os resultados das análises de solo, e os tratos culturais e fitossanitários, conforme preconizados para as culturas componentes dos consórcios com a bananeira 'Terra'.

\section{RESULTADOS E DISCUSSÃO}

Os coeficientes técnicos gerados, por produto, encontram-se na Tabela 1, relativos aos dois ciclos de produção, onde se observa que o item que mais influenciou no custo total foi a colheita, seguida de insumos, em relação aos três produtos (milho, feijão e caupi) avaliados, conforme discutido e analisado em seguida.

Os resultados obtidos com as culturas intercalares - milho, feijão e caupi -, relativos às produtividades alcançadas, custos operacionais, receitas e índice de rentabilidade convertidos para hectare, são mostrados

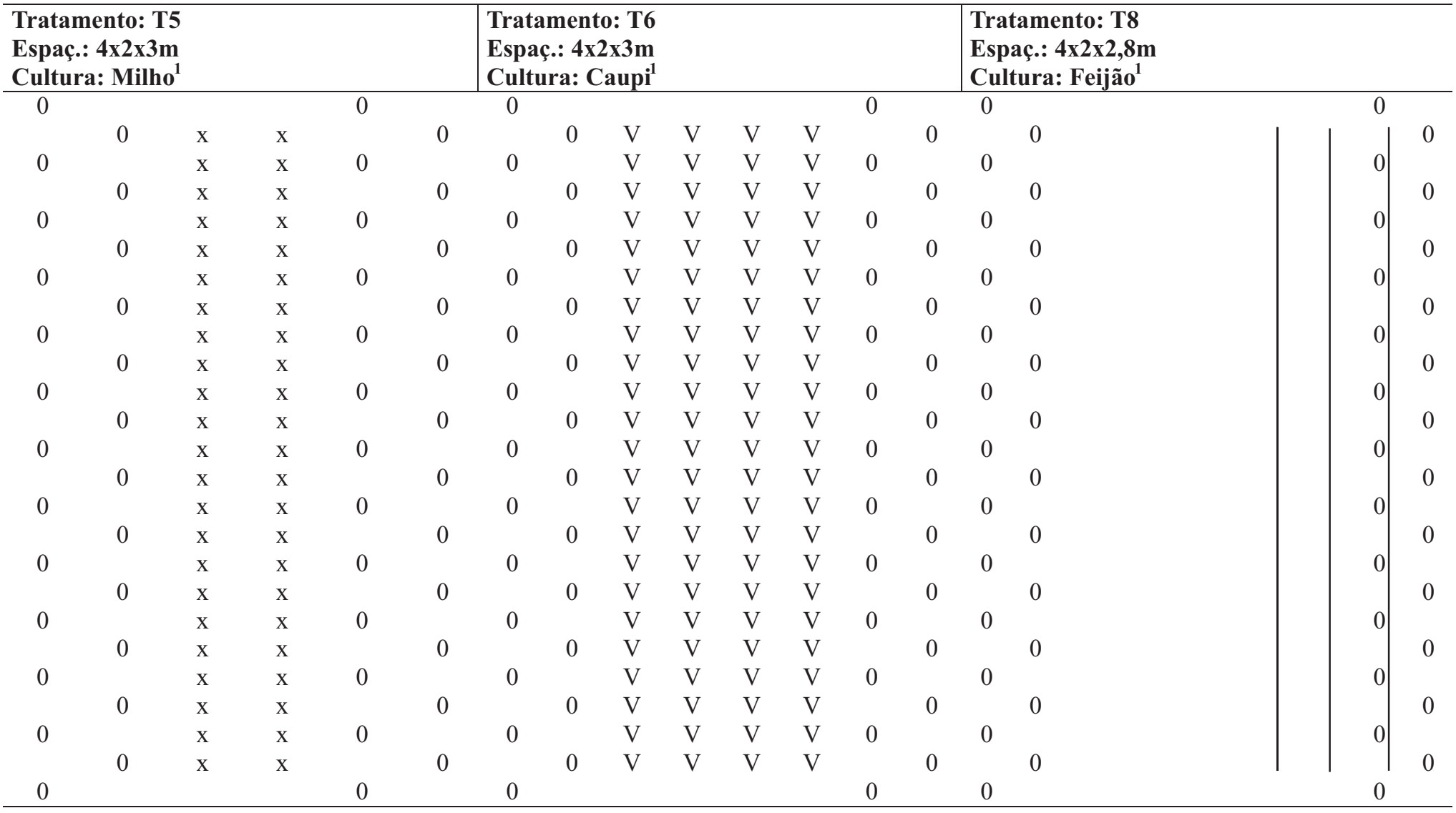

0 = Banana $\mathrm{x}=$ Milho; $\mathrm{V}=$ Caupi $\mathrm{I}=$ Feijão

${ }^{1}$ Nos demais tratamentos consorciados $\left(\mathrm{T}_{2}, \mathrm{~T}_{3}, \mathrm{~T}_{4}\right.$ ), os arranjos foram os mesmos, por cultura. No $\mathrm{T}_{7}$, plantou-se Feijão-de-porco, para cobertura do solo, conforme explicitado na sua descrição.

FIGURA 1 - Arranjos espaciais dos consórcios de bananeira 'Terra' com culturas alimentícias. 
TABELA 1 - Despesas e receitas (ha) relativas ao milho, feijão e caupi consorciados com bananeira 'Terra' em Teolândia, Litoral Sul da Bahia - 2002.

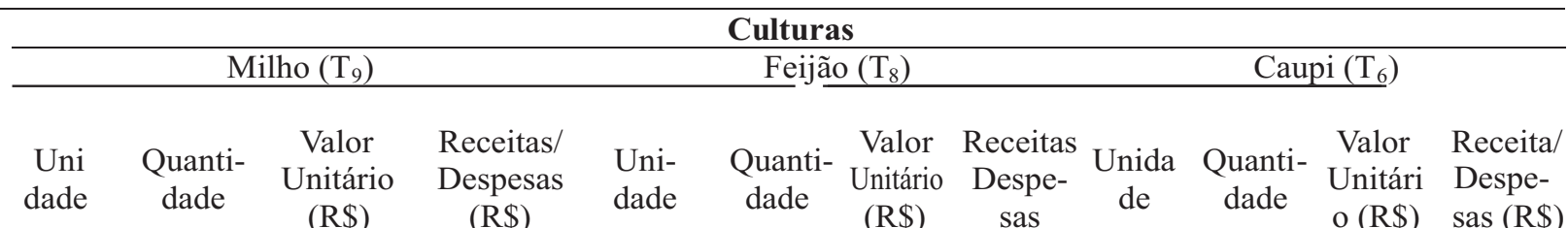
$(\mathrm{R} \$)$

\begin{tabular}{|c|c|c|c|c|c|c|c|c|c|c|c|c|}
\hline \\
\hline & & & & & & & & & & & & \\
\hline \multicolumn{9}{|l|}{$\begin{array}{l}\text { Insumos: } \\
\text { Semente }(2)^{1}\end{array}$} & & & & \\
\hline Superfosfato simples-P & $\mathrm{kg}$ & 40 & 0,36 & 14,40 & $\mathrm{~kg}$ & 120 & 0,36 & 43,20 & $\mathrm{~kg}$ & 120 & 0,36 & 43,20 \\
\hline Uréia $(1 p+1 C)^{2}-N$ & $\mathrm{~kg}$ & 180 & 0,56 & 100,80 & $\mathrm{~kg}$ & 40 & 0,56 & 22,40 & $\mathrm{~kg}$ & 60 & 0,56 & 33,60 \\
\hline Cloreto de potássio $(1 p)^{2}-K$ & $\mathrm{~kg}$ & 40 & 0,48 & 19,20 & $\mathrm{~kg}$ & 90 & 0,48 & 43,20 & $\mathrm{~kg}$ & 80 & 0,48 & 38,40 \\
\hline Ac Mirex & $\mathrm{kg}$ & 1 & 7,00 & 7,00 & $\mathrm{~kg}$ & 1 & 7,00 & 7,00 & $\mathrm{~kg}$ & 1 & 7,00 & 7,00 \\
\hline Sacaria $^{3}$ & um & - & - & - & - & - & - & 10,20 & - & - & - & - \\
\hline \multicolumn{4}{|l|}{ Subtotal } & 166,20 & & & & 228,00 & & & & 164,20 \\
\hline \multicolumn{13}{|l|}{ Plantio } \\
\hline Abetura de covas $(2)^{1}$ & $\mathrm{D} / \mathrm{H}$ & 4 & 8,00 & 32,00 & $\mathrm{D} / \mathrm{H}$ & 8 & 8,00 & 64,00 & $\mathrm{D} / \mathrm{H}$ & 6 & 8,00 & 48,00 \\
\hline Adubação das covas (NPK) & $\mathrm{D} / \mathrm{H}$ & 2 & 8,00 & 16,00 & $\mathrm{D} / \mathrm{H}$ & 2 & 8,00 & 16,00 & $\mathrm{D} / \mathrm{H}$ & 2 & 8,00 & 16,00 \\
\hline Plantio $(2)^{2}$ & $\mathrm{D} / \mathrm{H}$ & 4 & 8,00 & 32,00 & $\mathrm{D} / \mathrm{H}$ & 8 & 8,00 & 64,00 & $\mathrm{D} / \mathrm{H}$ & 6 & 8,00 & 48,00 \\
\hline \multicolumn{4}{|l|}{ Subtotal } & 80,00 & & & & 144,00 & & & & 112,00 \\
\hline \multicolumn{13}{|l|}{$\begin{array}{l}\text { Tratos culturais e } \\
\text { fitossanitários }\end{array}$} \\
\hline Controle do mato & $\mathrm{D} / \mathrm{H}$ & 16 & 8,00 & 128,00 & $\mathrm{D} / \mathrm{H}$ & 16 & 8,00 & 128,00 & $\mathrm{D} / \mathrm{H}$ & 16 & 8,00 & 128,00 \\
\hline Adub. $\mathrm{N}$ em cobertura (2) & $\mathrm{D} / \mathrm{H}$ & 2 & 8,00 & 16,00 & - & - & - & - & $\mathrm{D} / \mathrm{H}$ & 2 & 8,00 & 16,00 \\
\hline Controle de pragas & $\mathrm{D} / \mathrm{H}$ & 1 & 8,00 & 8,00 & $\mathrm{D} / \mathrm{H}$ & 1 & 8,00 & 8,00 & $\mathrm{D} / \mathrm{H}$ & 1 & 8,00 & 8,00 \\
\hline \multicolumn{3}{|l|}{ Subtotal } & & 152,00 & & & & 136,00 & & & & 152,00 \\
\hline \multicolumn{13}{|l|}{ Colheita e transporte } \\
\hline Colheita $(2)^{1}$ & $\mathrm{D} / \mathrm{H}$ & 12 & 8,00 & 96,00 & $\mathrm{D} / \mathrm{H}$ & 12 & 8,00 & 96,00 & $\mathrm{D} / \mathrm{H}$ & 12 & 8,00 & 96,00 \\
\hline Transporte da produção & $\mathrm{D} / \mathrm{H}$ & 4 & 8,00 & 32,00 & $\mathrm{D} / \mathrm{H}$ & 4 & 8,00 & 32,00 & $\mathrm{D} / \mathrm{H}$ & 4 & 8,00 & 32,00 \\
\hline \multicolumn{3}{|l|}{ Subtotal } & & 128,00 & & & & 128,00 & & & & 128,00 \\
\hline \multicolumn{4}{|l|}{ TOTAL } & 526,20 & & & & 636,00 & & & & 556,20 \\
\hline \multicolumn{13}{|l|}{ Produção e receita ${ }^{4}$} \\
\hline Produção & \multicolumn{3}{|c|}{$\begin{array}{l}352 \text { centos de } \\
\text { espigas de }\end{array}$} & & & \multirow{2}{*}{\multicolumn{2}{|c|}{$\begin{array}{l}2.000 \mathrm{~kg} \text { de } \\
\text { feijão }\end{array}$}} & & & \multirow{2}{*}{\multicolumn{2}{|c|}{$\begin{array}{c}3.030 \text { litros de } \\
\text { Feijão verde } \\
\text { em caroço }\end{array}$}} & \\
\hline Receita total & milhs & erde & & $3.520,00$ & & & & $2.154,00$ & & & & $3.030,00$ \\
\hline
\end{tabular}

${ }^{1}$ Relativo a dois cultivos; ${ }^{2}$ Aplicação no plantio e em cobertura; ${ }^{3}$ Por conta do comprador; ${ }^{4} \mathrm{~A}$ preços de 2001.

na Tabela 2, onde se observa que houve produtividades relativamente baixas para alguns tratamentos, principalmente por terem sido originárias de dois cultivos sucessivos. As produtividades crescentes ou decrescentes de tratamento para tratamento foram devidas, principalmente, a efeitos do gradiente de fertilidade do solo e, em menor grau, à utilização mais adequada ou menos adequada das tecnologias e insumos.

As vendas de milho sob a forma de espigas verdes e as de caupi, como feijão verde, deveram-se à alternativa do próprio produtor, que geralmente obtém melhores preços com esta modalidade de comercialização, o que contribui para um incremento na receita total.

A produtividade do feijão $(1.500-2.000 \mathrm{~kg} / \mathrm{ha})$ foi considerada significativa para as condições de sequeiro, tendo sido bem superior à média nacional $(600 \mathrm{~kg} / \mathrm{ha})$.

Os custos operacionais foram mais elevados para o feijão, atingindo a média de $\mathrm{R} \$ 614,95 / \mathrm{ha}$, seguido do caupi com $\mathrm{R} \$ 506,35 / \mathrm{ha}$ e do milho com $\mathrm{R} \$ 495,80$. Observa-se que os custos operacionais mais altos estão geralmente associados a maiores produtividades, sendo, portanto, uma decorrência de mais operários utilizados na colheita, fato este ocorrido nos tratamentos $\mathrm{T}_{9}$ (milho), $\mathrm{T}_{6}$ (caupi) e $\mathrm{T}_{8}$ (feijão), como se observa na Tabela 1.

No que concerne à receita líquida, os melhores resultados são devidos ao milho comercializado sob a forma de centos de espiga de

TABELA 2 - Produtividade, custos operacionais, receitas e índice de rentabilidade/ha das culturas de milho, feijão e caupi intercaladas com bananeira, em dois cultivos sucessivos em Teolândia, Litoral Sul da Bahia - 2002.

\begin{tabular}{|c|c|c|c|c|c|}
\hline $\begin{array}{c}\text { Consórcio } \\
\qquad(T)^{1}\end{array}$ & $\begin{array}{l}\text { Produtividade } \\
\text { (kg/ha) }\end{array}$ & $\begin{array}{c}\text { Custo operacional } \\
(R \$ / h a)(C)\end{array}$ & $\begin{array}{c}\text { Receita total } \\
(R \$ / h a)(R)\end{array}$ & $\begin{array}{l}\text { Receita líquida } \\
\quad(R)-(C)\end{array}$ & $\begin{array}{c}\text { Índice de } \\
\text { rentabilidade (IR) } \\
(R) \div(C)\end{array}$ \\
\hline Bananeira $x$ milho $-T_{2}$ & $41,28^{3}$ & 451,00 & 412,80 & $-38,20$ & 0,91 \\
\hline Bananeira $x$ milho $-T_{5}$ & $69,69^{3}$ & 510,20 & 696,90 & 186,70 & 1,36 \\
\hline Bananeira $x$ milho $-T_{9}$ & $352^{3}$ & 526,20 & $3.520,00$ & $2.993,80$ & 6,68 \\
\hline Bananeira $x$ caupi $-T_{3}$ & $618^{4}$ & 456,50 & 618,00 & 161,50 & 1,35 \\
\hline Bananeira $x$ caupi $-T_{6}$ & $3030^{4}$ & 556,20 & $3.030,00$ & $2.473,80$ & 5,75 \\
\hline Bananeira $x$ feijão $-T_{4}$ & 1571 & 593,90 & $1.996,00$ & $1.402,10$ & 3,36 \\
\hline Bananeira $x$ feijão $-T_{8}$ & 2000 & 636,00 & $2.514,18$ & $1.878,18$ & 3,95 \\
\hline
\end{tabular}

${ }^{1} \mathrm{~T}=$ Tratamentos. $\mathrm{O}$ tratamento $\mathrm{T}_{1}$ não figura por se tratar de sistema não consorciado e o $\mathrm{T}_{7}$ pela cultura intercalar ter sido o feijão-de-porco, utilizado como cobertura viva do solo.

${ }^{2}$ Valor a ser agregado à Receita Líquida obtida da bananeira.

${ }^{3}$ Centos de espigas de milho verde. Houve ataque da lagarta-do-cartucho-do-milho no segundo cultivo.

${ }^{4}$ Litros de feijão caupí verde. 
milho verde e ao caupi sob a forma de litros de feijão verde, respectivamente, seguidos do feijão carioquinha seco, em quilograma, os quais vão agregar um significativo valor à cultura da bananeira, quando da composição da sua receita líquida.

Com base nos índices de rentabilidade, observa-se que apenas o tratamento $\mathrm{T}_{2}$ apresentou efeito negativo, com índice de rentabilidade (IR) de 0,91, atribuído principalmente ao ataque da lagarta do cartucho do milho, Spodoptera frugiperda, não agregando valor à cultura principal - a bananeira -, mas disponibilizando outra fonte e alimento - o milho , para consumo familiar e alimentação de animais. O IR 0,91 implica que, para cada real investido, houve um prejuízo de aproximadamente $\mathrm{R} \$$ 0,09 . No entanto, o tratamento $T_{5}$, também com milho, já apresentou efeito positivo, com índice de rentabilidade de 1,36, o que vale dizer que, para cada real investido em insumos de produção, houve um retorno de $\mathrm{R} \$ 1,36$. Já no tratamento $\mathrm{T}_{9}$, o milho apresentou produtividade, receita total, receita líquida e índice de rentabilidade expressivos, ou seja, 352 centos de espigas de milho verde/ha, com receita total de $\mathrm{R} \$ 3.520,00$, receita líquida de $\mathrm{R} \$ 2.993,80$ e índice de rentabilidade de 6,68, em decorrência das tecnologias e insumos utilizados, o que vai permitir a agregação de um elevado valor à cultura da bananeira. Este índice de rentabilidade importa dizer que, para cada real investido na cultura do milho, houve um retorno de $\mathrm{R} \$ 6,68$. $\mathrm{O}$ tratamento $\mathrm{T}_{3}$, relativo ao consórcio bananeira x caupi, apresentou produtividade média e baixas receitas total e líquida, agregando pouco valor à bananeira.

$\mathrm{O}$ índice de rentabilidade foi de 1,35 , ou seja, um retorno de $\mathrm{R} \$$ 1,35 por real investido, em relação às tecnologias e insumos utilizados.

Por outro lado, no tratamento $\mathrm{T}_{6}$, o caupi gerou efeitos bem mais positivos sobre a produtividade, representada por 3030 litros de feijão caupi verde/ha, receita total de $\mathrm{R} \$ 3.030,00$, receita líquida de $\mathrm{R} \$$ $2.473,80$ e índice de rentabilidade de 5,75, o qual implica um retorno de $\mathrm{R} \$$ 5,75 para cada real investido, que vai agregar um valor significativo à

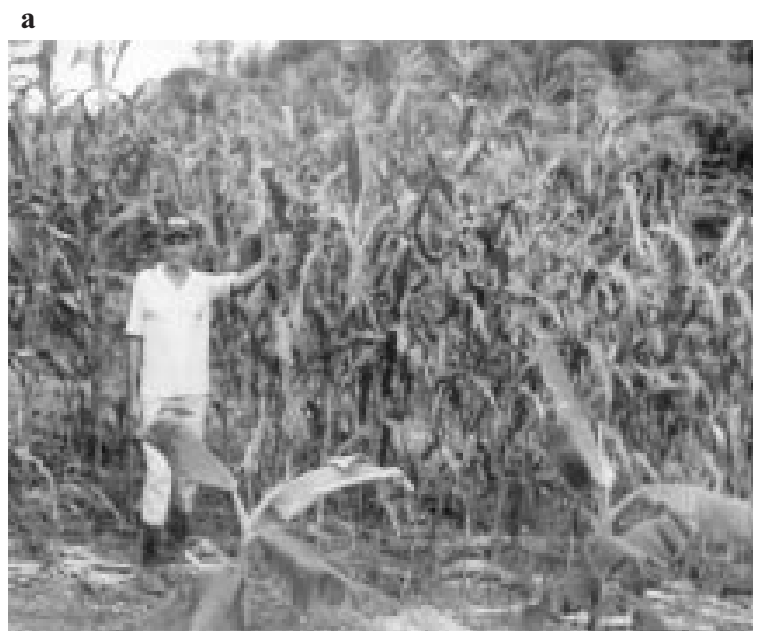

cultura da bananeira.

O consórcio bananeira $\mathrm{x}$ feijão, representado pelos tratamentos $\mathrm{T}_{4}$ e $\mathrm{T}_{8}$, apresentaram, também, efeitos positivos quanto ao uso de tecnologias e insumos modernos. Ambos geraram boas produtividades, receitas total e líquida, contribuindo significativamente para a agregação de importantes valores à cultura da bananeira. Os IRs de 3,36 e 3,95 implicam retornos de $\mathrm{R} \$ 3,36$ e $\$ 3,95$ por real investido, respectivamente.

Esses resultados são compatíveis com os obtidos por Santacruz S. \& Cardona T. (1988), que concluíram ser fácil introduzir melhorias nos sistemas tradicionais em consórcio e/ou associações de culturas alimentícias anuais, já que estas geralmente agregam valor à cultura principal. Belalcázar C. \& Cayón S. (1998) também constataram que os efeitos complementares das culturas consorciadas estão estritamente relacionados com as diferenças e ciclo e/ou espaçamentos das culturas envolvidas e com as tecnologias e insumos utilizados. Alves \& Coelho (1984) observaram que o espaçamento e a densidade de plantio da bananeira precisam ser adequados ao estabelecimento do consórcio e que a exploração mais intensiva da propriedade possibilita ao agricultor a obtenção de maior lucro ou, pelo menos, recuperar parcial ou totalmente os custos de implantação da bananeira. Belalcázar C. et al. (1995) constataram que se podem obter boas produções de milho e mandioca nos consórcios bananeira $\mathrm{x}$ milho e bananeira $\mathrm{x}$ mandioca, quando $\mathrm{o}$ estabelecimento do milho ou da mandioca se realiza nos primeiros estádios de desenvolvimento da bananeira, até a emissão da quarta folha.

Uma visão dos melhores tratamentos dos consórcios bananeira x milho, bananeira x feijão e bananeira x caupi, em Teolândia, Litoral Sul da Bahia, é mostrada na Figura 2.

\section{CONCLUSÕES}

As culturas do milho (Z. mays), feijão (P. vulgaris) e caupi ( $V$. unguiculata), com a adição de insumos e tecnologias apropriadas,

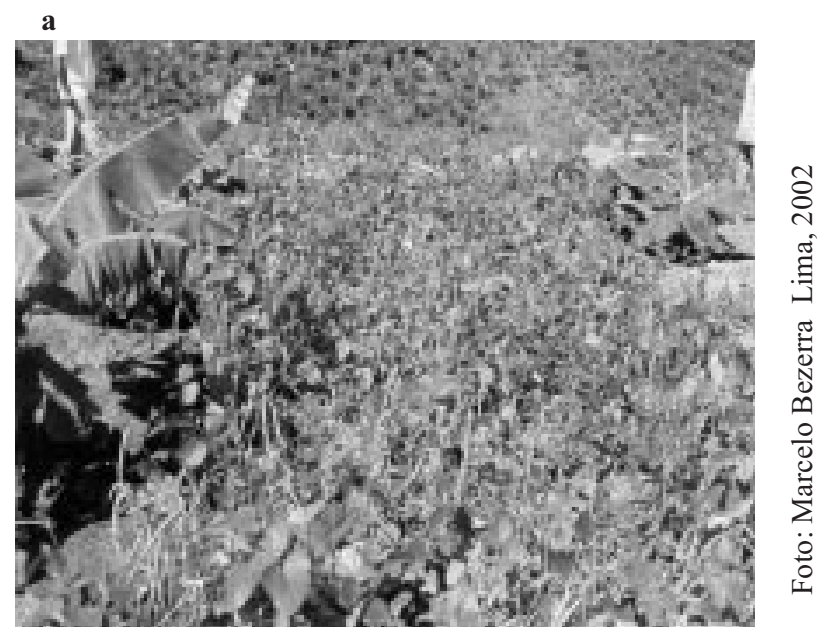

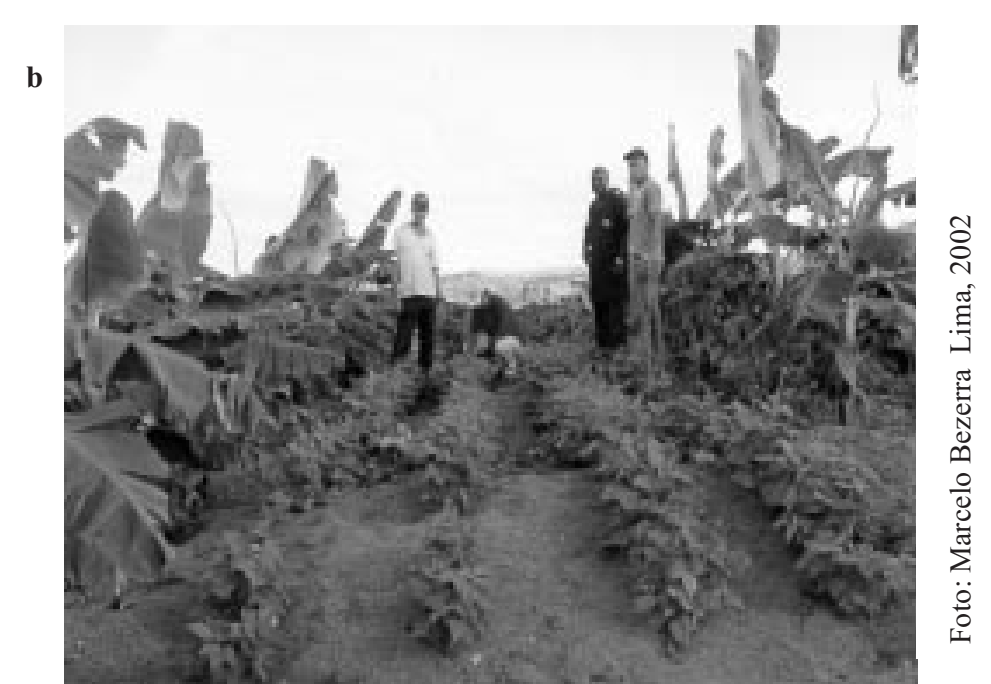

FIGURA 2 - Consórcios bananeira x milho e bananeira x caupi em primeiro cultivo (a), e bananeira x feijão em segundo cultivo (b). 
apresentaram produtividade, custo operacional, receita total, receita líquida e índice de rentabilidade, na sua maioria satisfatórios, quando consorciadas com bananeira 'Terra', nos arranjos espaciais adotados, agregando valor a esta cultura.

\section{REFERÊNCIAS}

ALVES, J.; COELHO, Y. da S. Consórcio de culturas alimentares com fruteiras. Informe Agropecuário, Belo Horizonte, v.10, n.118, p.6269, 1984.

ALVES, E.J. Consórcio da bananeira com culturas anuais, perenes e com plantas utilizadas para cobertura do solo. Cruz das Almas-BA: EMBRAPA-CNPMF, 2003 (Circular Técnica) no prelo.

BELALCÁZAR, C.S.L.; CAYÓN, S. G. Sistemas de producción. In: SEMINÁRIO INTERNACIONAL SOBRE PRODUCCIÓN DE PLATANO, 1., 1998, Quindio. Memorias... Quindio: Universidad del Quindio, Comité de Cafeteros del Quindio, Servício Nacional de Aprendizage Regional, 1998. p.137-146.

BELALCÁZAR, C.S.L. El cultivo del platano (Musa AAB Simmonds) en el trópico. Cali, Colombia: Impresora Feriva, 1991.376p.
BELALCÁZAR, C. S.L.; VALENCIA, M.J.A; ARCILAP.M.I. Influencia de la asociación de maiz y yuca sobre el crescimiento, desarrollo y producción de plátano del clon Dominico Hartón, Musa AAB Simmonds. In: . Mejoramiento de la producción del cultivo de plátano. Quindio: ICA, Comité Departamental de Cafeteros de Quindio/CIID/CORPOICA, INIBAP-LAC/INPOFOS, 1995.p.72-77.

DEVOS, P.; WILSON, G.F. Intercropping of plantains with food crops, maize, cassava and cocoyams. Fruits, Paris, v.34, n.3, p.169-174, jan., 1979.

MOURA, P.A.M. de. Alguns indicadores para análise econômica do consórcio feijão e milho. Informe Agropecuário, Belo Horizonte, v.10, n.118, p.3-10, out., 1984.

ROBINSON, J.C. Systems of cultivation and management. In: GOWEN, S. Ed. Banana and Plantains. London: Chapmans \& Hall, 1995. cap. 2, p.15-65.

SANTACRUZ, S.R.; CARDONA, T.J.H. Evaluación de sistemas de cultivos asociados con plátano (Musa p.). In: REUNIÓN ACORBAT, 8., 1987, Santa Marta, Colombia. Memorias... Medellin, Colombia: Asociación de Bananeros de Urabá, 1988. p.495-512. 